Graphical Abstract eps
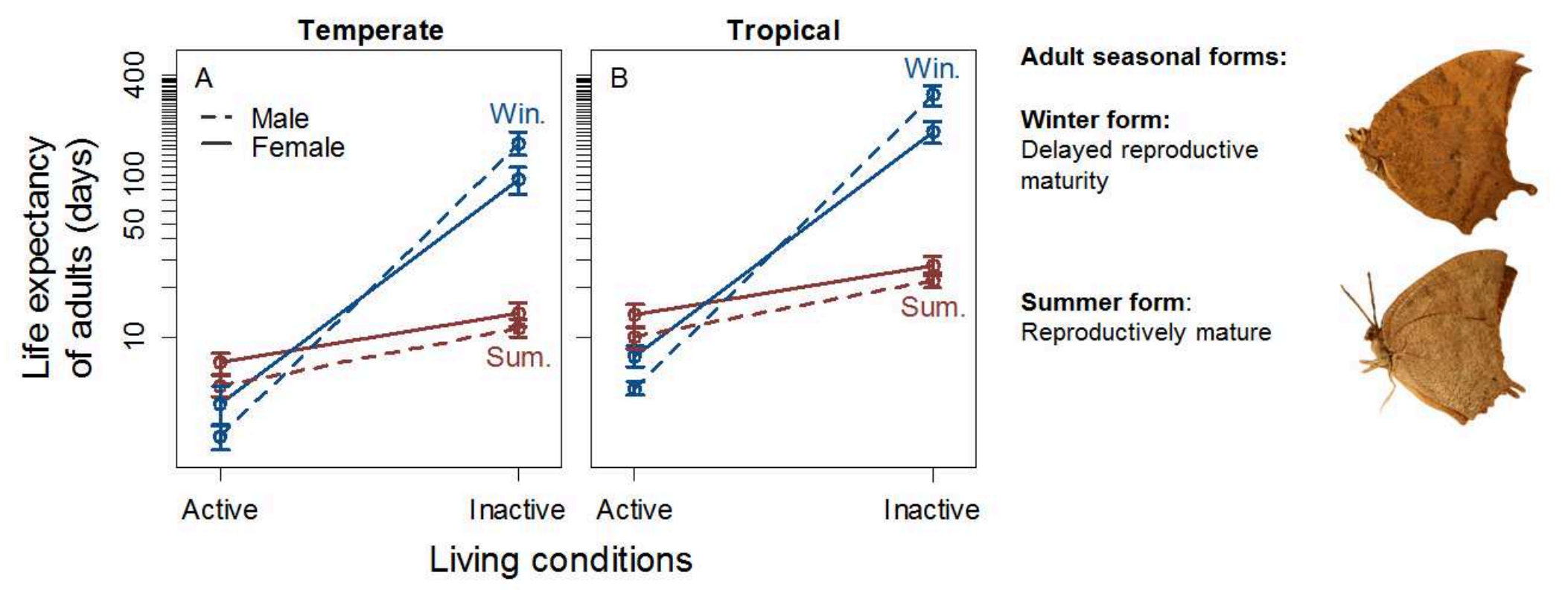


\title{
Seasonal life history trade-offs in two leafwing butterflies: delaying reproductive development increases life expectancy
}

\author{
Robert M. McElderry ${ }^{1}$ \\ University of Miami, Coral Gables, Florida, U.S.A. 33146; and Fairchild Tropical \\ Botanic Garden, Miami, Florida, U.S.A. 33156.
}

\begin{abstract}
Surviving inhospitable periods or seasons may greatly affect fitness. Evidence of this exists in the prevalence of dormant stages in the life cycles of most insects. Here I focused on butterflies with distinct seasonal morphological types (not a genetic polymorphism) in which one morphological type, or form, delays reproduction until favorable conditions return, while the other form develops in an environment that favors direct reproduction. For two butterflies, Anaea aidea and A. andria, I tested the hypothesis that the development of each seasonal form involves a differential allocation of resources to survival at eclosion. I assayed differences in adult longevity among summer and winter forms in either a warm, active environment or a cool, calm environment. Winter form adults lived 40 times longer than summer form but only in calm, cool conditions. The magnitude of this difference provided compelling evidence that the winter form body plan and metabolic strategy (i.e. resource conservatism) favor long term survival. This research suggests that winter form adults maintain lowered metabolic rate, a common feature of diapause, to conserve resources and delay senescence while overwintering.

Keywords: Life history trade-off; seasonal life history; longevity; reproductive diapause; resource allocation; Anaea spp.
\end{abstract}

${ }^{1}$ rmcelderry@bio.miami.edu 


\section{Introduction}

In variable environments, survival of harsh conditions has the greatest impact on fitness, especially for short-lived organisms (Morris et al., 2008). The ability of organisms to store nutrients and energy can provide an important 5 buffer against the difficulties presented by environments that change state on a temporal scale that is shorter than the lifetime of organisms. One important example is seasonality, a pattern in which the environment changes state on a regular basis each year. In response to seasonality, many insects are capable of entering into diapause or a similar dormant state in which they can endure 10 periods of otherwise unsuitable conditions (Hahn and Denlinger, 2011). Diapause serves not only to allow insects to endure unsuitable conditions, but also synchronizes the life cycle with seasonal resource dynamics (Hahn and Denlinger, 2011). In addition to storing resources, diapausing insects can reduce their metabolism to conserve energy reserves (Hahn and Denlinger, 2011). Although diapause has typically received attention in temperate regions, where unsuitable conditions occur during the winter, diapause has also gained attention for its prevalence during summer (Masaki, 1980) and also among tropical species where dry seasons may restrict suitable conditions (Denlinger, 1986).

20 In this paper, I explored adult longevity in leafwing butterflies, genus Anaea (Nymphalidae). I focused on two leafwing species with broad geographic distributions, one from tropical latitudes, and the other from temperate latitudes. Co-occurrence of these Anaea in Texas provides the opportunity to compare seasonality between a tropical and temperate butterfly in a subtropical climate. There are two distinct seasonal forms of adult Anaea (Riley, 1980) that diverge in life history. Winter form adults develop in the fall and survive the winter to reproduce in the spring, while summer form adults develop in the spring and reproduce in the summer and fall (Riley, 1980). The development of each seasonal form is day length dependent (Riley, 1988a), so they do not represent genetic-based polymorphisms. These seasonal forms are morphologically (Riley, 1980) and physiologically distinct (Riley, 1988b), suggesting the differential allocation of resources to survival and reproduction. Summer form Anaea are reproductively viable as early as two days following adult emergence, while winter form individuals are re-

35 productively non-viable for at least one month after emerging (pers. obser., Riley, 1988b).

Many butterflies depend on the resources acquired as caterpillars Boggs, 
1997), meaning the energy budget is set before eclosing as adults. Thus resource allocation to survival and reproduction has typically been evaluated simply by the pattern of resource distribution throughout the bodies of adults at eclosion. In general larger female butterflies allocate an increased proportion of both biomass and nitrogen to the abdomen for reproduction (Wickman and Karlsson, 1989), suggesting that when butterflies obtain sufficient resources to survive, any remaining resources are allocated to reproduction. However, in butterfly seasonal forms the allocation patterns differ in the proportion of resources invested in either survival or reproduction. An experiment comparing winter and summer forms in Polygonia c-album, a butterfly with similar life history to Anaea, found that winter form adults invested a higher proportion of resources to the thorax compared with the abdomen (soma versus reproduction) (Karlsson and Wickman, 1989). In other words, winter form adults allocate resources preferentially to survival. Summer form females invested a higher proportion of body mass and total nitrogen to the abdomen relative to the thorax (Karlsson and Wickman, 1989), representing preferential investment in reproduction. Within these seasonal forms there is a clear switch in investment strategies, but to evaluate whether or not this switch constitutes a trade-off, we need to evaluate the fitness cost.

A trade-off, by definition, is an observed negative association between life history traits that implies differential allocation of limited resources to one function vs another at particular times in the life cycle (Zera and Harshman, 2001). The observed allocation is expected to be the one that has the highest fitness, such that alternative allocations would have lower fitness (Stearns, 1989). For example if a species allocates all its energy to growth and survival during the early years, but allocates a substantial portion of energy to reproduction later in life, it is expected that altering this allocation pattern, for example reproducing early, would result in lower fitness. The link between the preferential investment in the abdomen and fecundity has been well established across insects, with increased abdomen size resulting in increased fecundity (Garca-Barros, 2000; Karlsson and Wickman, 1990; Wickman and Karlsson, 1989). However, increased life expectancy resulting from preferen70 tial investment in the somatic tissues has not been experimentally verified, although winter form butterflies do seem to live longer in nature. I asked if summer form adults are capable of achieving the same life expectancy if provided the same living conditions as winter form adults. Important to this question is the finding that preferential allocation of larval-obtained re75 sources to the abdomen decreases in species that forage for nitrogen-rich food 
as adults (Boggs, 1981). Several butterflies, including Anaea and Polygonia feed on potentially nitrogen rich foods, e.g., rotting fruit, fermenting sap, or dung (Scott, 1992). If resources are not limiting, then how important is the preferential investment in reproduction over survival at eclosion if adult feeding can balance resource needs?

I tested the hypothesis that the development of each seasonal form involves differential allocation of resources to survival at eclosion, which will result in differences in life expectancy. Using the fact that the development of each seasonal form is photoperiod dependent (Riley, 1988a), I created each seasonal form in the laboratory. I recorded adult size at eclosion and measured the time to death for each adult under two experimental living conditions. I subjected adults of each seasonal form to either a warm, sunny environment that encouraged an active lifestyle similar to foraging adults in the summer, or to a cool, calm environment that encouraged inactivity of individuals similar to quiescence in winter. To remove resource limitation, I continuously supplied adults with fermenting bananas and water. I presumed that adult size at eclosion corresponds to the size of resource reserves and included size as a covariate in the analysis to control for differences in adult life expectancy due to adult size alone. I predicted summer form adults vive better when inactive. Further, I expected larger adults to live longer based on resource allocation patterns documented for Polygonia (Karlsson and Wickman, 1989). Although adult feeding and lack of reproductive activity in summer form adults might offset resource needs in favor of surviving, I expected that winter form adults would have longer life expectancy due to delayed reproductive development (Riley, 1988b).

\section{Methods}

I studied adult longevity for two leafwing butterflies Anaea andria and A. aidea (Nymphalidae), each from a different climate, temperate and tropical, respectively. Anaea andria (temperate leafwing) is distributed throughout the southeastern United States and Anaea aidea (tropical leafwing) is distributed throughout Central America (Scott, 1992). Anaea endure the winter as adults, as opposed to a majority of temperate butterflies that overwinter in a juvenile stage (Scott, 1992). Anaea aidea and A. andria exhibit two seasonal morphological types of adults called either winter and summer forms or dry and wet forms (Comstock, 1961). Day length regulates whether pupae 
will develop into summer versus winter form adults with photoperiods of at least 14 hours and winter form adults with photoperiods no longer than 12 hours (Riley, 1988a).

\subsection{Rearing of Butterflies}

I collected Anaea caterpillars from natural populations in Gainesville, Florida and Austin, Texas, and transported caterpillars along with local host plants Croton spp. to Miami, FL where I established a captive Anaea population. In Austin, I collected caterpillars from the Brackenridge Field Laboratory $\left(30^{\circ} 17^{\prime} 00^{\prime \prime} \mathrm{N}, 97^{\circ} 46^{\prime} 44^{\prime \prime} \mathrm{W}\right)$, and in Gainesville, I collected caterpillars

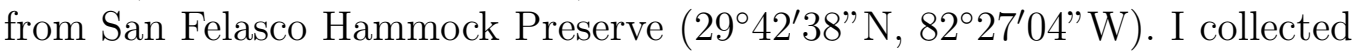
temperate leafwing from Gainesville and Austin, and tropical leafwing from Austin only on three separate occasions, April 2011, October 2012, and April 2013. The temperate leafwing was collected only from Gainesville in 2011 and in subsequent years only from Austin.

Once in Miami, I cultivated all host plants in a shade house at Fairchild Tropical Botanic Garden in Miami, FL. I placed wild-collected and captivebred eggs and caterpillars along with the leaf or a sprig of the host where they were attached in petri dishes with moistened filter paper. Each caterpillar was segregated into a separate petri dish and provided leaf material from the host plant on which it was found. I checked all individuals each day and cleaned the petri dish and replenished leaf material as needed. I moved all new fifth instar larvae from $9 \mathrm{~cm}$ diameter petri dishes to $15 \mathrm{~cm}$ dishes. After each caterpillar pupated, I inserted a cylindrical mesh screen between the bottom and lid of the petri dish to create a small cage $(15 \mathrm{~cm}$ height $\times$ $15 \mathrm{~cm}$ diameter). Adult butterflies emerged in these small cages still inside of the growth chamber and I provided each individual with a small puddle of water and fermenting banana mash for food (about $2 \mathrm{~mL}$ of each).

Caterpillars grew in a growth chamber (Percival Scientific I-35), under temperature conditions programmed to mimic natural conditions during the month of April. The temperature schedule in the growth chamber started each day with a slow increase from $20^{\circ} \mathrm{C}$ to $30^{\circ} \mathrm{C}$ over 7 hours after the lights turned on. After remaining at this warm temperature for three hours, the temperature then gradually dropped back down to $20^{\circ} \mathrm{C}$ in a series of steps over the next 10 hours. The temperature then remained at the minimum of $20^{\circ} \mathrm{C}$, and then the diurnal cycle repeated. Average daily temperature was $24.85^{\circ} \mathrm{C}$. The lighting schedule was constant for each cohort of caterpillars, but differed among cohorts to produce each seasonal form. I set 
the photoperiod to 14L:10D to produce summer form adults and 12L:12D to produce winter form adults (Riley, 1988a). Cohorts were maintained in identical conditions to reduce the chance of spurious differences between cohorts. Sample sizes for summer and winter form adults, respectively, were as follows: temperate (24 and 11 females, 16 and 2 males) and tropical (41 and 41 females, 40 and 51 males) leafwings.

To test for differences in life expectancy, I subjected adults of each seasonal form to one of two experimental living conditions. Experimental conditions were meant to mimic either (1) the conditions endured by summer form adults that do not enter a quiescent state or (2) the conditions endured by winter form adults that are quiescent through the winter and become active in the spring. To encourage an active life style, I kept butterflies outside in a shade house to represent a warm, sunny (20\% sunlight) environment where metabolism would be increased with warmth and activity, and individuals were free to fly in $1 \mathrm{~m}^{3}$ cages. Average summer temperatures in South Florida remain around $33^{\circ} \mathrm{C}$, and about $200 \mathrm{~mm}$ of rain falls on average each month from May to October (Chen and Gerber, 1990). To encourage an inactive life style, I kept butterflies inside the cool, dim laboratory where metabolism would be decreased, and individuals were essentially unable to fly in the small cylindrical cages. Conditions in the laboratory remained fairly consistent with an average temperature of $22^{\circ} \mathrm{C}$, and I provided a di12L:12D photoperiod. Butterflies of both seasonal forms were isolated at all times, preventing mating which could alter the allocation of resources. I checked each individual every day, and supplied fresh water and fermenting banana mash as needed until all butterflies died.

\subsection{Statistical analyses}

I used accelerated failure-time regression to evaluate adult life expectancy, i.e., the number of days from eclosion to death, in response to age, leafwing species, seasonal form, sex, forewing length, and experimental living conditions. Accelerated failure-time models are generalized linear models for which a number probability distributions can be tested, each with a direct link to how the probability of mortality and the instantaneous risk of mortality changes with age (Fox, 2001). I evaluated the appropriateness of four probability distributions, and in doing so I tested three alternative hypotheses; mortality was constant over all ages (exponential), mortality increased 


\section{Results}

The log-logistic probability distribution provided the best fit to the data $(\Delta \mathrm{AIC}$ : exponential $=88$, Weibull $=35, \log$-logistic $=0, \operatorname{lognormal}=41)$, indicating that mortality increased to a maximum at some age, then decreased. Using backward stepwise regression for model reduction, I excluded 22 non-significant interaction terms, and arrived at a model that included all factors and only four interactions. AIC model selection metrics supported this model with $65 \%$ likelihood relative to the other models in my stepwise approach (Table 1). Although forewing length explained only a fraction of 
the deviance that seasonal form and living conditions explained, it did explain a statistically significant amount of deviance (Table 2). Larger adults lived longer on average, and this result was not dependent on any other factor, i.e., all interactions were non-significant; so I evaluated the effect of all other factors at the mean forewing length to control for size effects. The significant interactions terms: treatment $\times$ season, treatment $\times$ sex, and treatment $\times$ season $\times$ sex, indicated that differences in life expectancy between winter and summer seasonal forms and also between the sexes depended on the experimental living conditions (treatment in Table 2). The interaction between season and sex indicates that seasonal differences in life expectancy are sex dependent, and the lack of significant interactions including leafwing species indicates that the effects of these factors and their interactions do not differ between the temperate and tropical leafwings (Table 2).

235 Winter form adults had the longest life expectancy, outliving summer form adults by a factor of almost 40 (Figure 1). However, this only occurred in the cool, dim environment, where individuals were encouraged to be inactive. In the warm, sunny environment, where individuals were encouraged to be active, winter form adults had much lower life expectancy than summer form adults (Figure 1). There was a much smaller difference in life expectancy for summer adults between active and inactive living conditions than there was for winter form adults, but similar to winter adults, summer adults did live longer when encouraged to be inactive (Figure 1). This pattern was more pronounced for males than it was for females (Figure 1).

245 Females lived longer on average, but had lower life expectancy than males when inactive and in the winter form. Tropical leafwing lived longer than temperate leafwing regardless of sex, seasonal form, or activity level (Figure 1 ), but this result was marginally significant.

\section{Discussion}

$250 \quad$ For butterflies with seasonal forms, winter (dry) season forms delay reproductive maturity to survive until breeding season conditions return in spring (Brakefield and Reitsma, 1991; Karlsson and Wickman, 1989; Torres et al., 2009). I experimentally verified for both Anaea aidea (tropical) and A. andria (temperate) that by delaying reproductive development, winter form adults 255 do achieve much greater live expectancy than summer form adults that do not delay reproductive development. The maximum life span achieved was 466 days (oviposition to death). Fruit feeding butterflies have been shown 
to have relatively long lives in nature with one individual observed living at least 293 days (Molleman et al., 2007). The great disparity in life expectancy between seasonal forms provides compelling evidence that the winter form body plan and metabolic strategy favors long term survival. Resources used for reproduction are not available for maintenance (Stearns, 1989; Zera and Harshman, 2001), and the fact that winter form leafwing delay reproductive maturity (Riley, 1988b) and increase life expectancy in doing so suggested that these resources were used for maintenance to survive.

My research also showed that adult feeding had little impact on the differences between seasonal forms, which seems contradictory to research showing increased life expectancy with high quality diets (e.g., Molleman et al., 2008a b). Karlsson (1994) linked food quality with the change in thorax to omen as butterflies age, showing that aging Heliconius hecale increased in thorax and abdomen mass due to a nitrogen-rich diet of pollen, while two nectar feeders, Parage aegeria and Speyeria mormonia, decreased primarily in abdomen mass. However, restricted diet and mass were not predictors of life expectancy in S. mormonia in a study by Boggs and Ross (1993), which the authors suggest was due to decreased reproductive output to reallocate resources to survival. Similarly, (Molleman et al., 2008a) showed decreased life expectancy with increased reproductive rate for Bicyclus anynana, but Molleman et al. (2008b) did not find this cost for Charaxes fulvescens. My results demonstrated that adult feeding did not offset the cost of reproductive development paid by summer form adults. Winter form adults delayed this cost, and achieved greater life expectancy. The finding that adult size in my study was positively correlated with life expectancy suggests some reliance on stored resources obtained as larvae. However, life expectancy only changed a small amount relative to changes in adult size. A millimeter dif285 ference in forewing length predicted little more than an extra day of life on average, and the maximum difference in forewing length among adults was only $12 \mathrm{~mm}$.

The energy budget of diapausing, aestivating, or quiescent adults responds to resource reserves, income, and conservation. The results reported here discount large effects of either reserves or income, but strongly support a difference in resource conservation. Differing morphology between seasonal forms already suggested different physiology, e.g. delayed reproductive development (Riley, 1988b), and the extreme difference in life expectancy between seasonal forms was striking. Summer form adults were simply unprepared to survive as long as winter form adults. The fact that this result was only 
true in a cool calm environment supports resource conservation, given that warmer temperatures increase metabolism. Lower temperatures have been linked to decreased resting metabolic rates for adults (Pijpe et al., 2007) and greatly increases life expectancy (Bauerfeind et al., 2009; Hahn and Denlinger, 2011; Wikström et al., 2009). Lowered metabolic rate decreases resource demands reducing the need to be active, which also conserves energy. Insects have multiple physiological pathways for sensing resource reserves (Hahn and Denlinger, 2011), and starvation as adults actually increases life expectancy of fruit-feeding butterflies (Pijpe et al., 2007, 2008). The level of feeding activity varied among individuals in our study, but most butterflies appeared at rest most of the time, and fed infrequently. The inability to survive in the warm, active environment shows that the longevity of winter form adults required quiescence to achieve high life expectancy, which is important when considering the effects of warming climates on overwintering 310 butterflies (see WallisDeVries et al., 2011).

Summer form adults lived short lives whether active or inactive, which indicates that these butterflies would only have limited aestivation abilities to survive during inhospitable periods. The fact that I did not allow mating for either seasonal form controlled for seasonal differences that would result from the cost of reproduction. The age of the oldest summer form adult was 126 days which is very similar to the time between spring and fall breeding seasons, about 120 days from May to September. Austin has a subtropical climate with two inhospitable seasons (NWS, 2015), which differs from either temperate climates to the north where $A$. andria occurs or tropical climates to the south where $A$. aidea occurs. The wet-dry seasons in Mexico are comparable in timing and duration to the summer-winter seasons in United States, meaning the tropical $A$. aidea is able to endure either winter or the dry season depending on its latitude. However, summers may be especially hot and dry in Texas, making recruitment difficult for butterflies when fresh foliage is hard to find and creating a situation where survival strategies are optimal. Similar to other Texas butterflies in this environment (Gilbert, 1985), leafwing likely retreat to wetter, shaded habitats along rivers and streams, where conditions are more favorable. This behavior has also been documented for tropical butterflies (Brakefield and Reitsma, 1991; Denlinger, 1986). 


\subsection{Conclusions}

I found a striking difference in life expectancy between seasonal morphological types of adults for a tropical and temperate leafwing, A. aidea and A. andria, in a subtropical environment. Although the tropical leafwing outlived the temperate leafwing, the pattern of differences in response to sex, season, and living conditions was unchanged between species. Winter adults outlived summer adults, but only in a calm, cool environment. My results suggest that winter adults achieved high life expectancy not just through resource storage, but also resource conservatism.

\section{Acknowledgments}

I thank Lawrence E. Gilbert for advice in butterfly rearing. The University of Texas Brackenridge Field Laboratory, Florida Department of Environmental Protection (permit 03011112), and the USDA Forest Service (permit LAK300) provided access to collection sites. Funding from the Lisa D. Anness Fellowship and facilities at Fairchild Tropical Botanical Garden and the University of Miami supported this project. Comments from Carol C. Horvitz, Joyce Maschinski, L.E. Gilbert, Donald L. DeAngelis, J. Albert C. Uy and two anonymous reviewers improved this manuscript.

\section{References}

Bauerfeind, S. S., Perlick, J. E., Fischer, K., 2009. Disentangling environmental effects on adult life span in a butterfly across the metamorphic boundary. Experimental Gerontology 44 (12), 805-811.

Boggs, C. L., 1981. Nutritional and life-history determinants of resource allocation in holometabolous insects. American Naturalist 117 (5), 692-709.

Boggs, C. L., 1997. Reproductive allocation from reserves and income in butterfly species with differing adult diets. Ecology 78 (1), 181-191.

Boggs, C. L., Ross, C. L., 1993. The effect of adult food limitation on life history traits in Speyeria mormonia(Lepidoptera: Nymphalidae). Ecology, 433-441.

Brakefield, P. M., Reitsma, N., 1991. Phenotypic plasticity, seasonal climate and the population biology of Bicyclus butterflies (Satyridae) in Malawi. Ecological Entomology 16 (3), 291-303. 
Burnham, K. P., Anderson, D. R., 2002. Model selection and multimodel inference: a practical information-theoretic approach. Springer.

Chen, E., Gerber, J. F., 1990. Climate. In: Myers, R., Ewel, J. (Eds.), Ecosystems of Florida. University of Central Florida Press, Orlando, FL, p. 765 .

Comstock, W., 1961. Butterflies of the American tropics, the genus Anaea Lepidoptera Nymphalidae: a study of the species heretofore included in genera Anaea, Coenophlebia, Hypna, Polygrapha, Protogonius, Siderone and Zaretis. American Museum of Natural History.

Denlinger, D. L., 1986. Dormancy in tropical insects. Annual Review of Entomology 31 (1), 239-264.

Fox, G. A., 2001. Failure-time analysis. In: Scheiner, S. M., Gurevitch, J. 375 (Eds.), Design and Analysis of Ecological Experiments. Oxford University Press.

Garca-Barros, E., 2000. Body size, egg size, and their interspecific relationships with ecological and life history traits in butterflies (Lepidoptera: Papilionoidea, Hesperioidea). Biological Journal of the Linnean Society 70 (2), 251-284.

Gilbert, L., 1985. Ecological factors which influence migratory behavior in two butterflies of the semi-arid shrublands of south Texas. In: Rankin, M. (Ed.), Migration: Mechanisms and Adaptive Significance. University of Texas at Austin, pp. 724-747.

Hahn, D. A., Denlinger, D. L., 2011. Energetics of insect diapause. Annual Review of Entomology 56, 103-121.

Karlsson, B., 1994. Feeding habits and change of body composition with age in three nymphalid butterfly species. Oikos 69, 224-230.

Karlsson, B., Wickman, P.-O., 1989. The cost of prolonged life: an experi390 ment on a nymphalid butterfly. Functional Ecology 3 (4), 399-405.

Karlsson, B., Wickman, P.-O., 1990. Increase in reproductive effort as explained by body size and resource allocation in the speckled wood butterfly, Pararge aegeria (L.). Functional Ecology 4, 609-617. 
Masaki, S., 1980. Summer diapause. Annual Review of Entomology 25 (1),

NWS N., $\quad 2015$. $2015 . \quad$ Austin climate summary (http://www.srh.noaa.gov/images/ewx/climate/ausclisum.pdf).

Pijpe, J., Brakefield, P. M., Zwaan, B. J., 2007. Phenotypic plasticity of starvation resistance in the butterfly Bicyclus anynana. Evolutionary Ecology 21 (5), 589-600.

Pijpe, J., Brakefield, P. M., Zwaan, B. J., 2008. Increased life span in a polyphenic butterfly artificially selected for starvation resistance. The American Naturalist 171 (1), 81-90.

Riley, T. J., 1980. Effects of long and short day photoperiods on the seasonal dimorphism of Anaea andria (Nymphalidae) from central Missouri. Journal of the Lepidopterists Society 34 (4), 330-337.

Riley, T. J., 1988a. Effect of larval photoperiod on incidence of adult seasonal forms in Anaea andria (Lepidoptera: Nymphalidae). Journal of the Kansas Entomological Society 61 (2), 224-227. 
425

430

435

WallisDeVries, M. F., Baxter, W., Van Vliet, A. J., 2011. Beyond climate envelopes: effects of weather on regional population trends in butterflies. Oecologia 167 (2), 559-571.

Wickman, P.-O., Karlsson, B., 1989. Abdomen size, body size and the repro440

Wikström, L., Milberg, P., Bergman, K.-O., 2009. Monitoring of butterflies in semi-natural grasslands: diurnal variation and weather effects. Journal of Insect Conservation 13 (2), 203-211.

Zera, A. J., Harshman, L. G., 2001. The physiology of life history trade-offs 445

Riley, T. J., 1988b. Effect of larval photoperiod on mating and reproductive diapause in seasonal forms of Anaea andria (Nymphalidae). Journal of the Lepidopterists Society 42 (4), 263-268.

Scott, J. A., 1992. The butterflies of North America: a natural history and field guide. Stanford University Press.

Stearns, S. C., 1989. Trade-offs in life-history evolution. Functional Ecology 3 (3), 259-268.

Torres, C., Osorio-Beristain, M., Mariano, N. A., Legal, L., 2009. Sexdependent seasonal feeding activity variations among two species of Nymphalidae (Lepidoptera) in the Mexican tropical dry forest. Annales de la Societe Entomologique de France 45, 265-274.

ductive effort of insects. Oikos 56 (2), 209-214. 


\section{Tables}

Table 1: Model selection criteria among competing models predicting time to death of adult butterflies with leafwing species, seasonal form, sex, and living conditions as factors and the covariate forewing length. The column Step indicates the step in the backward stepwise regression model reduction process. The best model had the following structure: $\log ($ time to death $)=$ treatment + season + leafwing + sex + forewing length + treatment $\times$ season + treatment $\times$ sex + season $\times$ sex + treatment $\times$ season $\times$ sex, where treatment refers to the experimental living conditions and season refers to the seasonal form

\begin{tabular}{cccccc}
\hline Model & Step & \# Par. & AICc & AICc & Weight \\
\hline 1 & 6 & 11 & 1684 & 0.00 & 0.65 \\
2 & 5 & 12 & 1685 & 1.67 & 0.28 \\
4 & 3 & 20 & 1689 & 5.71 & 0.04 \\
5 & 4 & 17 & 1691 & 7.29 & 0.02 \\
6 & 2 & 21 & 1692 & 8.10 & 0.01 \\
7 & 1 & 26 & 1703 & 19.53 & 0.00 \\
8 & 0 & 29 & 1708 & 24.84 & 0.00 \\
\hline
\end{tabular}


Table 2: Analysis of deviance table for the accelerated failure-time model predicting time to death of adult butterflies with the factors, leafwing species, seasonal form, sex, and living conditions and the covariate forewing length (Model 1, Table 1). I used a $\chi^{2}$ test for the significance of the amount of deviance explained by each factor. The fit of the model to the data, i.e., the total deviance explained, was significant ( $\mathrm{df}=9, \chi^{2}=363.78, \mathrm{p}<$ $0.001)$.

\begin{tabular}{|c|c|c|c|c|c|}
\hline Factor & df & Deviance & $\begin{array}{c}\text { Residual } \\
\text { df }\end{array}$ & $\begin{array}{l}\text { Residual } \\
\text { Deviance }\end{array}$ & p-value \\
\hline Treatment & 1 & 145.3 & 223 & 1879 & $<0.001$ \\
\hline Season & 1 & 32.8 & 222 & 1846 & $<0.001$ \\
\hline Leafwing & 1 & 3.9 & 221 & 1842 & 0.048 \\
\hline Sex & 1 & 13.8 & 220 & 1828 & $<0.001$ \\
\hline Forewing Length & 1 & 14.8 & 219 & 1813 & $<0.001$ \\
\hline Treatment Season & 1 & 137.6 & 218 & 1676 & $<0.001$ \\
\hline Treatment Sex & 1 & 6.9 & 217 & 1669 & 0.009 \\
\hline Season Sex & 1 & 2.4 & 216 & 1667 & 0.120 \\
\hline Treatment Season Sex & 1 & 6.2 & 215 & 1660 & 0.013 \\
\hline Intercept only & & & 224 & 2024 & \\
\hline
\end{tabular}




\section{Figure captions}

Figure 1. Interaction plots comparing the mean ( \pm SE) life expectancy between males (dashed) and females (solid) of each seasonal form of the 450 temperate, A. andria (A), and tropical, A. aidea (B), leafwings. Living conditions refers to one of two experimental conditions for adults. Active conditions were maintained outside in a shade house and represent a warm, sunny environment where butterflies were able to fly. Inactive conditions were maintained inside a laboratory and represent a cool, low light environment

455 where butterflies were unable to fly. 
Figure 1:

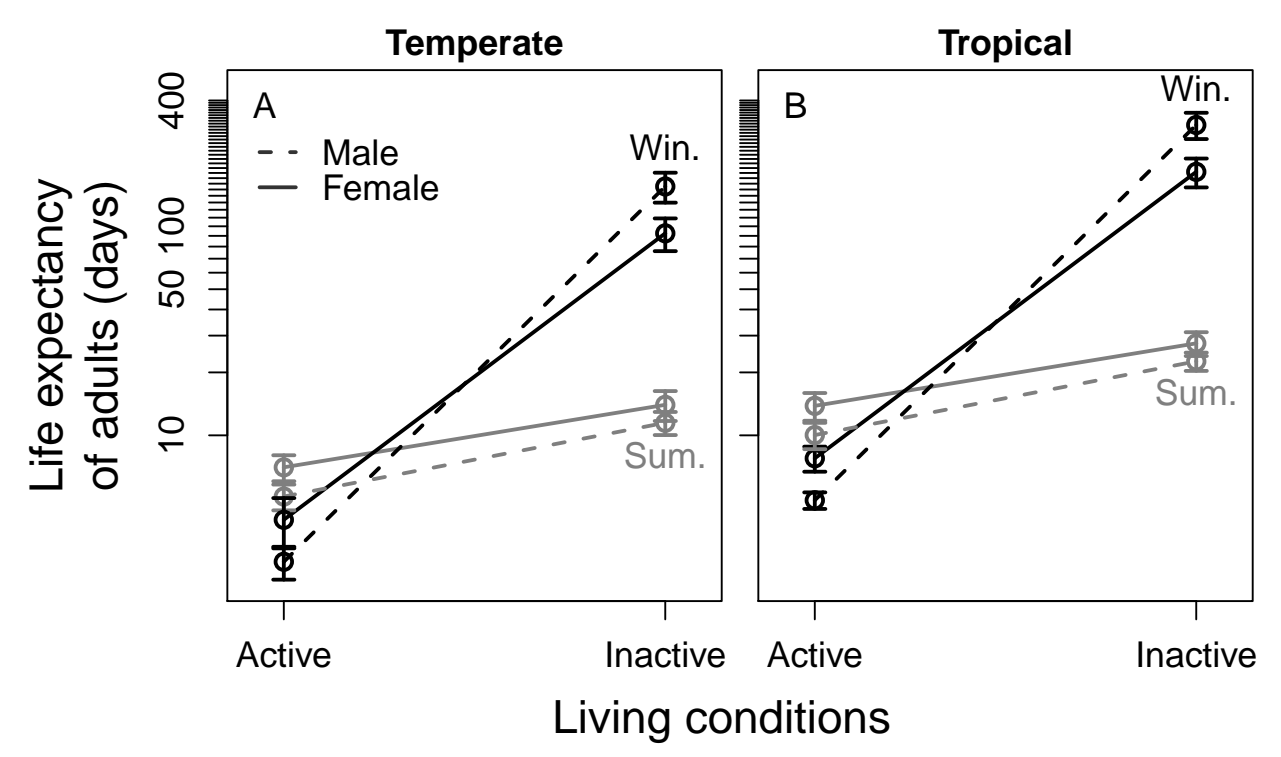

34

35

36

37

38

39

40

41

42

43

44

45

46

47

48

49

50

51

52

53

54

55

56

57

58

59 